\title{
Achieving the Goals of Dementia Plans: A Review of Evidence-Informed Implementation Strategies
}

\author{
Atteindre les objectifs fixés dans le cadre des plans \\ contre la démence : revue des stratégies de mise en \\ œuvre éclairées par les données probantes
}

\author{
5 \\ MATTHEW HACKER TEPER, BA, MSC \\ Researcher, Department of Family Medicine, Faculty of Medicine \\ McGill University \\ Montreal, QC \\ CLAIRE GODARD-SEBILLOTTE, MD \\ PhD Candidate, Department of Family Medicine, Faculty of Medicine \\ McGill University \\ Montreal, QC \\ ISABELLE VEDEL, MD-MPH, PHD \\ Assistant Professor, Department of Family Medicine, Faculty of Medicine \\ McGill University \\ Montreal, QC
}

\begin{abstract}
A 2019 report by the Canadian Academy of Health Sciences identified the importance of evidence-informed implementation strategies in reforming dementia care. Such implementation strategies may be relevant to changing clinical practice in the wake of Canada's impending federal dementia plan (initiated by Bill C-233). As this federal dementia plan is elaborated, there may be value in looking ahead to some of the implementation challenges likely to be faced "on the ground" in healthcare settings. We thus conducted a rapid review
\end{abstract}


of provincial and national dementia plans from high-income countries and reviewed studies on implementation strategies to dementia care. We advance seven key implementation strategies that may be useful for future dementia care reform.

\section{Résumé}

Un rapport publié en 2019 par l'Académie canadienne des sciences de la santé met en relief l'importance des stratégies éclairées par les données probantes pour la mise en œuvre des réformes des soins en matière de démence. Ces stratégies de mise en œuvre peuvent permettre de changer la pratique clinique dans le contexte imminent du plan fédéral canadien en matière de démence (au moyen du projet de loi C-233). Dans le contexte de ce plan, il est intéressant d'envisager certains défis liés à la mise en œuvre auxquels devront faire face «sur le terrain » les établissements de santé. Nous avons ainsi mené une revue rapide des plans provinciaux et nationaux contre la démence dans les pays à revenu élevé. Puis nous y avons examiné les stratégies de mise en œuvre pour les soins en matière de démence. Nous proposons sept stratégies de mise en œuvre qui pourraient être utiles pour d'éventuelles réformes des soins en matière de démence.

\section{The Alzheimer Society of Canada (20io) reports that by 2038 over 1.1 million Canadians will have dementia. This represents $2.8 \%$ of the total Canadian L population, with $9 \%$ of Canadians over age 60 and $50 \%$ of Canadians over age 90} having dementia (Alzheimer Society of Canada 2010). Ultimately, this prevalence of dementia will lead to a cumulative economic burden of $\$ 293$ billion per year by 2040 (Alzheimer Society of Canada 2018). In response to rising global dementia rates, the World Health Organization (WHO 2012) has identified dementia as a global health priority. In Canada, this priority has been addressed provincially: beginning with Ontario in 1999 (MOHLTC 1999), provinces have gradually developed plans to address the overwhelming scale, impact and cost of dementia. While provincial stewardship in this arena is logical (Flood and Choudhry 2002), calls for a federal dementia strategy that is complementary to provincial stewardship - involving investment in research, increasing awareness of dementia risk factors and supporting and inspiring local clinicians to improve care practices for dementia - persist (Alzheimer Society of Canada 2018).

Canada's recent passage of Bill C-233, an Act respecting a national strategy for Alzheimer's disease and other dementias, suggests that a federal dementia plan may soon be established. Bill C-233 identified five priorities for dementia care reform: (1) developing national objectives, (2) encouraging investment in research, (3) coordinating with international bodies (e.g., WHO), (4) assisting provinces with the development and dissemination of 
diagnostic treatment guidelines and best practices for dementia care management; and (5) making recommendations for standards of care. A National Dementia Conference (PHAC 2018) and a report conducted by the Canadian Academy of Health Sciences (CAHS 2019) were organized in response to Bill C-233. Both the conference and report allowed for diverse stakeholders to share perspectives on dementia care and support, research and public education. They also suggested that implementing a dementia strategy is easier said than done. Accordingly, the CAHS recommended that evidence-informed implementation strategies be considered to achieve stated goals of dementia care reform (CAHS 2019). To respond to this final recommendation - and to support the clinic-level objectives identified by Bill C-233 and the National Dementia Conference - a synthesis of existing implementation strategies specifically relevant to dementia care is needed.

In this article, our aims are (1) to highlight why implementation strategies are essential components downstream of any dementia plan, (2) to examine the implementation strategies referenced in dementia plans of peer high-income countries and provinces; and (3) to review and propose evidence-informed implementation strategies that national and provincial governments in Canada may use as they further reform dementia care at the clinical level. To do so, we conducted a rapid review as defined by Tricco et al. (2016), examining provincial and national dementia plans from around the world. In addition, we reviewed studies on implementation strategies that are specific to dementia care reform. Note that while a dementia plan should ideally be broad, including supportive housing, community programs, caregiver support, dementia-friendly cities, transportation and anti-stigma campaigns, this paper will specifically focus on the healthcare delivery system for dementia care.

\section{Why Implementation Strategies Matter}

The inclusion of implementation strategies in dementia care reform is important for countries to reap the benefits - improved care and reduced cost - of dementia plans (Milstein and Shortell 2012). Studies have shown that the dissemination of healthcare initiatives is challenging. For example, Damschroder et al. (2009) report that only one-third of healthcare improvement initiatives successfully transition from adoption to sustained implementation across organizations. Even if implementation strategies to change clinical practice are only enacted after high-level policy is negotiated, understanding implementation challenges likely to be faced by healthcare professionals is relevant to the negotiation of funding mechanisms and resource allocation by federal and provincial governments.

Whereas many implementation strategies are applicable to any healthcare policy, specific implementation strategies matter for dementia because of the complex nature of dementia diagnosis, care and affected population. First, dementia is notoriously underdiagnosed in primary care, with rates between one-half (Bradford et al. 2009) and two-thirds (Valcour et al. 2000). The challenges of primary care physicians to diagnose dementia stem from a lack of confidence (Foley et al. 2017) and/or uncertainty about whether the diagnosis of an 
incurable disease such as dementia will improve the care or quality of life of a patient (Borson and Chodosh 2014). Second, optimal dementia care requires a wide range of personnel and services, which change as the needs of dementia patients evolve (Borson and Chodosh 2014). Third, patients with dementia suffer from high degrees of comorbidity, with one-third of patients experiencing five or more additional chronic conditions (Mondor et al. 2017). Acute exacerbations of these co-existing diseases often make dementia care too rare of a priority. Finally, optimal dementia care requires engaging both the patient and their caregiver(s), which is specific to dementia care (Borson and Chodosh 2014).

\section{Shedding Light on the Lack of Implementation Strategies in Published National and Provincial Plans for Dementia}

National and provincial plans for dementia have been published in 29 countries and eight Canadian provinces, according to Alzheimer's Disease International (2018). We analyzed the 24 strategies that were written in either English or French (16 countries plus all eight Canadian provinces). These reports generally share a common form: the reports define dementia and describe its prevalence and impact, underscore the purpose for a national or provincial dementia strategy and outline strategic priorities for dementia reform.

These priorities typically include (1) increasing awareness and understanding of dementia, (2) promoting timely diagnosis through workforce development; and (3) improving dementia management and care. Of the 24 national and provincial plans for dementia examined, only 12 addressed the implementation strategies for the programs. The plans either introduce implementation strategies throughout the documents (i.e., tying individual strategies to specific objectives) or through explicit "stand-alone" chapters on implementation strategies, typically located towards the conclusion of the documents (Table 1).

More critically, even among the national and provincial plans for dementia that include sections on implementation strategies, very few plans actually articulate strategies for the diffusion or implementation of dementia care reform. They tend to state objectives but not how such objectives will be achieved or measured (e.g., "educating more people earlier about the risks of developing dementia"). The few implementation strategies that have been articulated remain vague. Strategies like "investing in research" (United Kingdom) (United Kingdom Department of Health 2009), "diversifying pedagogical approaches" (France) (Ministère des Affaires sociales, de la Santé et des Droits des femmes 2014) and "involving individuals living with dementia and their caregivers" (Switzerland and Malta) (Office fédéral de la santé publique 2013; Scerri 2014) form inadequate foundations upon which governments can orchestrate targeted and consequential steps towards achieving dementia plan goals. 
TABLE 1. A list of reviewed national and provincial dementia plans, and how they address implementation strategies

\begin{tabular}{|c|c|c|c|}
\hline Region & Implementation & $\begin{array}{l}\text { Integrated } \\
\text { throughout plan }\end{array}$ & $\begin{array}{l}\text { Stand-alone } \\
\text { section }\end{array}$ \\
\hline \multicolumn{4}{|l|}{ Country } \\
\hline Australia & $\checkmark$ & • & \\
\hline \multicolumn{4}{|l|}{ Finland } \\
\hline France & $v$ & - & \\
\hline Greece & $\checkmark$ & - & \\
\hline Indonesia & $\checkmark$ & - & \\
\hline Ireland & $\checkmark$ & & - \\
\hline \multicolumn{4}{|l|}{ Israel } \\
\hline \multicolumn{4}{|l|}{ Italy } \\
\hline Korea & $\checkmark$ & - & \\
\hline \multicolumn{4}{|l|}{ Luxembourg } \\
\hline Malta & $\checkmark$ & & - \\
\hline \multicolumn{4}{|l|}{ Netherlands } \\
\hline \multicolumn{4}{|l|}{ Norway } \\
\hline \multicolumn{4}{|l|}{ Switzerland } \\
\hline United Kingdom & $\checkmark$ & - & \\
\hline United States & $\checkmark$ & • & \\
\hline \multicolumn{4}{|c|}{ Canadian Province } \\
\hline \multicolumn{4}{|l|}{ Alberta } \\
\hline \multicolumn{4}{|l|}{ British Columbia } \\
\hline Manitoba & $\checkmark$ & • & \\
\hline \multicolumn{4}{|c|}{ Newfoundland \& Labrador } \\
\hline \multicolumn{4}{|l|}{ Nova Scotia } \\
\hline \multicolumn{4}{|l|}{ Ontario } \\
\hline Quebec & $\checkmark$ & & • \\
\hline Saskatchewan & $v$ & - & \\
\hline
\end{tabular}

\section{A Review of Successful Implementation Strategies in Dementia Care}

The literature suggests that any implementation of dementia reform, like any innovation, should target both individual adopters (healthcare professionals and informal caregivers) and whole organizations (Greenhalgh et al. 2004). Individual adopters benefit from 
pragmatic guidelines that target the confidence and expertise of individuals, address their concerns and encourage them to engage with dementia reform over an extended period. Implementation strategies should also be conceived at the organizational level, where integrating reforms with the current organizational context, identifying and valourizing a "champion" of dementia reform and providing additional resources and incentives may facilitate improved dementia care.

\section{Successful Strategies at the Individual Level: Putting People First}

\section{Disseminating pragmatic guidelines and training through active, concise and} varied formats

Traditional didactic and passive strategies (lecture-style meetings, printed materials and guidelines) are usually ineffective strategies for increasing healthcare professionals' knowledge of dementia and their confidence in managing patients (Aminzadeh et al. 2012; Burgio et al. 2001; Gifford et al. 1999). Healthcare professionals benefit most from problem-based and solution-focused dementia training (Yaffe et al. 2008). Whatever the intervention, strategies that focus on pragmatic benefit and usability should be developed (Aminzadeh et al. 2012). Guidelines must recognize the importance of the patient-caregiver dyad, which is specific to dementia (CAHS 2019). For example, caregivers benefit from specialized training including practice opportunities, personalized feedback and collaboration with practitioners (Chesney et al. 2011; Mazmanian and Davis 2002; Soumerai 1998). Guidelines to healthcare professionals and informal caregivers should be communicated in succinct and synchronized trainings to minimize "guideline fatigue" (Aminzadeh et al. 2012). These guidelines should also include recent recommendations from the Fourth Canadian Consensus Conference on the Diagnosis and Treatment of Dementia (Gauthier et al. 2012). Finally, guidelines should be encompassing of the comorbidity associated with dementia that often compounds physicians' difficulty with diagnosing and providing care for dementia and patients' difficulty with living with the disease while managing other chronic conditions (Borson and Chodosh 2014; Mondor et al. 2017).

\section{Promoting confidence and expertise}

Implementation strategies must be designed to target the confidence of healthcare professionals who feel ill-equipped to diagnose and care for dementia in Canada (Aminzadeh et al. 2012). Confident healthcare professionals are more likely to take a keen interest in dementia and dementia care reform and to diagnose dementia in a timely way (Aminzadeh et al. 2012; Moore and Cahill 2012). Confidence and expertise may be self-initiated, but governments can also furnish this capacity by providing funding and resources to train additional staff, such as geriatric nurses, who can collaborate and mentor closely with other clinicians (Aminzadeh et al. 2012). 


\section{Addressing concerns of potential adopters}

Similarly, many healthcare professionals approach dementia diagnosis and care from a nihilist perspective (Pentzek et al. 2009). Family physicians are concerned about whether a diagnosis will improve the quality of life of a patient (Borson and Chodosh 2014) and whether dementia care interventions will result in improved care (Black and Fauske 2007; Netting and Williams 1999; Seddon and Robinson 2001). Studies show that when healthcare professionals maintain negative attitudes towards dementia interventions, the interventions are less likely to be adopted (Khanassov et al. 2014). A final unique barrier remains the reluctance of some family physicians to be trained in dementia care by non-physicians (Cameron et al. 2010).

\section{Encouraging adopters to engage with the intervention over an extended period} Interventions take time to implement, and practices take time to change. This is especially true in dementia care, which mobilizes multiple health and social service organizations. Accordingly, benefits of dementia diagnosis and management take time to emerge. Persistence with interventions is thus particularly important in the context of dementia care. When healthcare professionals engage with new dementia programs for longer durations, their adherence to, and confidence in, the interventions increases (Cherry et al. 2004; Gladman et al. 2007; McCrae and Banerjee 2011; Netting and Williams 1999; Van Eijken et al. 2008). Eventually, as outcomes become perceivable, healthcare professionals feel increased self-worth and accomplishment (Grinberg et al. 2008).

\section{Successful Strategies at the Organizational Level: Teamwork and Resources}

\section{Integration with current context}

Dementia interventions that are implemented in ways that are compatible with the current healthcare structure are more likely to be well-received by healthcare professionals (Khanassov et al. 2014). This can be challenging, since dementia care is often time-consuming, especially for solo practitioners (Hinton et al. 2007). Team-based care, with a clear division of labour, is needed. For example, nurses (referred to as infirmières pivots, "pivot nurses") are particularly suited to conduct cognitive screening, assessment and functional evaluation (Bergman 2009).

\section{Identifying and valourizing a "champion" of dementia reform}

As is usually the case for any policy or program implementation, a critical predictor for the successful implementation of a strategy is the presence of a physician or nurse who serves as a "clear champion" for dementia reform (Gifford et al. 1999). This champion, who recognizes the potential benefits of new recommendations, including timely diagnosis of dementia and interdisciplinary management, takes an active role in convincing other colleagues to use the 
guidelines (Gifford et al. 1999). If the champion is knowledgeable in dementia management, they may also provide support and guidance to peers. Championing dementia reform can be individual- or team-based.

\section{Resources, incentives and culture}

Governments must also fund and support dementia-specific resources beyond the clinic: home-based care, community services, transportation, long-term care and assistive devices. Healthcare professionals should be trained to know which of these options or services are available in the region, how efficient and organized these resources are and how to refer patients to them (Yaffe et al. 2008). Governments should also consider personal incentives (such as remuneration and other motivations) and cultural differences (unique perceptions of dementia and caregiving, especially in rural, Northern or immigrant communities) when developing strategies for implementation (Braun and Browne 1998; Khanassov et al. 2014; Martindale-Adams et al. 2017).

\section{Limitations}

This rapid review serves as a brief overview of the current state of dementia plans, vis-àvis implementation strategies, across Canada and other high-income countries. However, our analysis is limited. First, untranslated dementia plans (written in languages other than English or French), or those not available in the public domain, were not examined. Also, this review was limited to national and provincial plans. Grey literature (including future policy enforcement documentation) was not examined. Accordingly, we may have missed more applied guidelines (including implementation strategies) in subsequent years.

\section{Summing Up: Implementation Strategies for Dementia}

Even if implementation strategies are not included in national and provincial dementia plans, they will ultimately be relevant to transforming dementia care practice "on the ground." This article advances several dementia-specific implementation strategies that can be leveraged to improve the diagnosis and management of dementia. These strategies should be considered as future dementia plans are translated from policy to action.

Correspondence may be directed to: Matthew Hacker Teper, Department of Family Medicine, Faculty of Medicine, McGill University, 5858, Chemin de la Côte-des-Neiges, 3rd Floor, Montreal, QC H3S 1Z1; e-mail: matthew.hackerteper@mail.mcgill.ca.

\section{References}

Alzheimer Society of Canada. 2010. "Rising Tide: The Impact of Dementia on Canadian Society." Retrieved April 30, 2018. <https://alzheimer.ca/sites/default/files/files/national/advocacy/asc_rising_tide_full_report_e. pdf $>$.

Alzheimer Society of Canada. 2018. "Alzheimer Society of Canada Calls for 'Alzheimer's Disease and Dementia Partnership.” Retreived May 3, 2018. <http://alzheimer.ca/en/Home/News-and-Events/feature-stories/ alzheimers-disease-dementia-partnership $>$. 
Alzheimer's Disease International. 2018. “Dementia Plans.” Retrieved March 29, 2018. <https://www.alz. co.uk/dementia-plans>.

Aminzadeh, F., F.J. Molnar, W.B. Dalziel and D. Ayotte. 2012. "A Review of Barriers and Enablers to Diagnosis and Management of Persons with Dementia in Primary Care." Canadian Geriatrics Journal 15(3): 85. doi: $10.5770 / \mathrm{cgj} .15 .42$.

Bergman, H. 2009. “Meeting the Challenge of Alzheimer's Disease and Related Disorders. A Vision Focused on the Individual, Humanism, and Excellence." Report on the Committee of Experts for the Development of an Action Plan on Alzheimer's Disease and Related Disorders.

Black, K. and J. Fauske. 2007. “Exploring Influences on Community-Based Case Managers' Advance Care Planning Practices: Facilitators or Barriers?" Home Health Care Services Quarterly 26(2): 41-58. doi: 10.1300/ J027v26n02_03.

Borson, S. and J. Chodosh. 2014. "Developing Dementia-Capable Health Care Systems: A 12-Step Program." Clinics in Geriatric Medicine 30(3): 395-420. doi: 10.1016/j.cger.2014.05.001.

Bradford, A., M.E. Kunik, P. Schulz, S.P. Williams and H. Singh. 2009. “Missed and Delayed Diagnosis of Dementia in Primary Care: Prevalence and Contributing Factors." Alzheimer Disease and Associated Disorders 23(4): 306-14. doi: 10.1097/WAD.0b013e3181a6bebc.

Braun, K.L. and C.V. Browne. 1998. “Perceptions of Dementia, Caregiving, and Help Seeking among Asian and Pacific Islander Americans." Health \& Social Work 23(4): 262-74. doi: 10.1093/hsw/23.4.262.

Burgio, L., K.L. Lichstein, L. Nichols, S. Czaja, D. Gallagher-Thompson, M. Bourgeois et al. 2001. "Judging Outcomes in Psychosocial Interventions for Dementia Caregivers: The Problem of Treatment Implementation." The Gerontologist 41(4): 481-89. doi: 10.1093/geront/41.4.481.

Cameron, M.J., M. Horst, L.W. Lawhorne and P.A. Lichtenberg. 2010. “Evaluation of Academic Detailing for Primary Care Physician Dementia Education." American Journal of Alzheimer's Disease \& Other Dementias 25(4): 333-39. doi: 10.1177/1533317510363469.

Canadian Academy of Health Sciences (CAHS). 2019. “Improving the Quality of Life and Care of Persons Living with Dementia and Their Caregivers." The Expert Panel on Dementia Care in Canada, CAHS.

Cherry, D.L., B.G. Vickrey, L. Schwankovsky, E. Heck, M. Plauchm and R. Yep. 2004. "Interventions to Improve Quality of Care: The Kaiser Permanente-Alzheimer's Association Dementia Care Project." American Journal of Managed Care 10(8): 553-60.

Chesney, T.R., B.E. Alvarado and A. Garcia. 2011. “A Mild Dementia Knowledge Transfer Program to Improve Knowledge and Confidence in Primary Care." Journal of the American Geriatrics Society 59(5): 942-44. doi: 10.1111/j.1532-5415.2011.03384.x

Damschroder, L.J., D.C. Aron, R.E. Keith, S.R. Kirsh, J.A. Alexander and J.C. Lowery. 2009. “Fostering Implementaiton of Health Services Research Findings into Practice: A Consolidated Framework for Advancing Implementation Science." Implementation Science 4(1): 50. doi: 10.1186/1748-5908-4-50.

Flood, C.M. and S. Choudhry. 2002. "Strengthening the Foundations: Modernizing the Canada Health Act." Discussion Paper No. 13, Royal Commission on the Future of Health Care in Canada. ISBN 0-662-32783-7.

Foley, T., S. Boyle, A. Jennings and W.H. Smithson. 2017. “We're Certainly Not in Our Comfort Zone': A Qualitative Study of GPs' Dementia-Care Educational Needs." BMC Family Practice 18(1): 66. doi: 10.1186/ s12875-017-0639-8.

Gauthier, S., C. Patterson, H. Chertkow, M. Gordon, N. Hermann, K. Rockwod et al. 2012.

"Recommendations of the 4th Canadian Consensus Conference on the Diagnosis and Treatment of Dementia (CCCDTD4)." Canadian Geriatrics Journal 15(49): 120-26. doi: 10.5770/cgj.15.49.

Gifford, D.R., R.G. Holloway, M.R. Frankel, C.L. Albright, R. Meyerson, R.C. Griggs et al. 1999. “Improving Adherence to Dementia Guidelines Through Education and Opinion Leaders: A Randomized, Controlled Trial." Annals of Internal Medicine 131(4): 237-46. doi: 10.1186/s12875-017-0639-8.

Gladman, J., R. Jones, K. Radford, E. Walker and I. Rothera. 2007. “Person-Centred Dementia Services Are Feasible, but Can They Be Sustained?" Age and Ageing 36(2): 171-76. doi: 10.1093/ageing/afl161. 
Greenhalgh, T., G. Robert, F. Macfarlane, P. Bate and O. Kyriakidou. 2004. "Diffusion of Innovations in Service Organizations: Systematic Review and Recommendations." The Milbank Quarterly 82(4): 581-629. doi: 10.1111/j.0887-378X.2004.00325.x.

Grinberg, A., J. Lagunoff, D. Phillips, B. Stern, M. Goodman and T. Chow. 2008. "Multidisciplinary Design and Implementation of a Day Program Specialized for the Frontotemporal Dementias." American Journal of Alzheimer's Disease \& Other Dementias 22(6): 499-506. doi: 10.1177/1533317507308780.

Hinton, L., C.E. Franz, G. Reddy, Y. Flores, R.L. Kravitz and J.C. Barker. 2007. “Practice Constraints, Behavioural Problems, and Dementia Care: Primary Care Physicians' Perspectives." Journal of General Internal Medicine 22(11): 1487-92. doi: 10.1007/s11606-007-0317-y.

Khanassov, V., I. Vedel and P. Pluye. 2014. "Case Management for Dementia in Primary Health Care: A Systematic Mixed Studies Review Based on the Diffusion of Innovation Model." Clinical Interventions in Aging 9: 915. doi: 10.2147/CIA.S64723.

Martindale-Adams, J., T. Tah, B. Finke, C. LaCounte, B.J. Higgins and L.O. Nichols. 2017. "Implementation of the REACH Model of Dementia Caregiver Support in American Indian and Alaska Native Communities." Translational Behavioral Medicine 7(3): 427-34. doi: 10-1007/s13142-017-0505-1.

Mazmanian, P.E. and D.A. Davis. 2002. "Continuing Medical Education and the Physician as a Learner: Guide to the Evidence." JAMA 288(9): 1057-60. doi: 10.1001/jama.288.9.1057.

McCrae, N. and S. Banerjee. 2011. "Modernizing Mental Health Services for Older People: A Case Study." International Psychogeriatrics 23(1): 10-19. doi: 10.1017/S1041610210001407.

Milstein, A. and S. Shortell. 2012. "Innovations in Care Delivery to Slow Growth of US Health Spending." JAMA 308(14): 1439-40. doi: 10.1001/jama.2012.12659.

Ministère des Affaires sociales, de la Santé et des Droits des femmes. 2014." Plan Maladies Neuro-Dégénératives." Retrieved April 17, 2018. <https://www.cnsa.fr/documentation/plan_maladies_neuro_degeneratives2014.pdf>.

Ministry of Health and Long-Term Care (MOHLTC). 1999. "Ontario's Strategy for Alzheimer Disease and Related Dementias. Government of Ontario." Retrieved April 17, 2018. <http://brainxchange.ca/Public/ Resource-Centre-Topics-A-to-Z/Ontario\%E2\%80\%99s-Strategy-for-Alzheimer-Disease-and-Relat.aspx>.

Mondor, L., C.J. Maxwell, D.B. Hogan, S.E. Bronskill, A. Grunier, N.E. Lane et al. 2017. “Multimorbidity and Healthcare Utilization among Home Care Clients with Dementia in Ontario, Canada: A Retrospective Analysis of a Population-Based Cohort." PLoS Medicine 14(3): e1002249. doi: 10.1371/journal.pmed.1002249.

Moore, V. and S. Cahill. 2012. "Diagnosis and Disclosure of Dementia - A Comparitive Qualiative Study of Irish and Swedish General Practitioners." Aging \& Mental Health 17(1): 77-84. doi: 10.1080/13607863.2012.692763.

Netting, F. E. and F.G. Williams. 1999. “Implementing a Case Management Program Designed to Enhance Primary Care Physician Practice with Older Persons." Journal of Applied Gerontology 18(1): 25-45. doi: 10.1080/13607863.2012.692763.

Office fédéral de la santé publique. 2013. "Stratégie nationale en matière de démence 2014-2017. Champs d'action." Retrieved April 17, 2018. <https://www.bag.admin.ch/bag/fr/home/strategie-und-politik/nationalegesundheitsstrategien/nationale-demenzstrategie.html>.

Pentzek, M., A. Wollny, B. Wiese, F. Jessen, F. Haller, W. Maier et al. 2009. “Apart from Nihilism and Stigma: What Influences General Practitioners' Accuracy in Identifying Incident Dementia?" The American Journal of Geriatric Psychiatry 17(11): 965-75. doi: 10.1097/JGP.0b013e3181b2075e.

Public Health Agency of Canada (PHAC). 2018. "Conference Report: National Dementia Conference. Inspiring and Informing a National Dementia Strategy for Canada. Government of Canada." Retrieved February 1, 2019. <https://www.canada.ca/content/dam/phac-aspc/documents/services/publications/diseasesconditions/national-dementia-conference-report/national-dementia-conference-report-eng.PDF>.

Scerri, C. 2014. "National Dementia Strategy: Malta 2015-2023. Valletta: Parliamentary Secretariat for Rights of Persons with Disability and Active Ageing." < https://activeageing.gov.mt/en/Documents/National\%20 Dementia\%20Strategy\%20-\%20Public\%20Consultation.pdf $>$.

Seddon, D. and C.A. Robinson. 2001. "Carers of Older People with Dementia: Assessment and the Carers Act." Health E Social Care in the Community 9(3): 151-58. doi: 10.1046/j.1365-2524.2001.00291.x. 
Soumerai, S.B. 1998. "Principles and Uses of Academic Detailing to Improve the Management of Psychiatric Disorders." The International Journal of Psychiatry in Medicine 28(1): 81-96. doi: 10.2190/ BTCA-Q06P-MGCQ-R0L5.

Tricco, A.C., W. Zarin, J. Antony, B. Hutton, D. Moher, D. Sherifali et al. 2016. "An International Survey and Modified Delphi Approach Revealed Numerous Rapid Review Methods." Journal of Clinical Epidemiology 70: 61-67. doi: 10.1016/j/clinepi.2015.08.012.

United Kingdom Department of Health. 2009. "Living Well with Dementia: A National Dementia Strategy. United Kingdom Department of Health." Retrieved April 17, 2018. <https://assets.publishing.service.gov.uk/ government/uploads/system/uploads/attachment_data/file/168220/dh_094051.pdf >.

Van Eijken, M., R. Melis, M. Wensing, M.O. Rikkert and T. Van Achterberg. 2008. “Feasibility of a New Community-Based Geriatric Intervention Programme: An Exploration of Experiences of GPs, Nurses, Geriatricians, Patients and Caregivers." Disability and Rebabilitation 30(9): 696-708. doi: 10.1080/09638280701400508.

Valcour, V.G., K.H. Masaki, J.D. Curb and P.L. Blanchette. 2000. “The Detection of Dementia in the Primary Care Setting." Archives of Internal Medicine 160(19): 2964-68. doi: 10.1001/archinte.160.19.2964.

World Health Organization (WHO). 2012. “Dementia: A Public Health Priority.” Retrieved March 29, 2018. $<$ https:/extranet.who.int/agefriendlyworld/wp-content/uploads/2014/06/WHO-Dementia-English.pdf >.

Yaffe, M.J., P. Orzeck and L. Barylak. 2008. “Family Physicians' Perspectives on Care of Dementia Patients and Family Caregivers." Canadian Family Physician 54(7): 1008-15. 